\title{
PERFIL DE RESISTENNCIA DE ISOLADOS DE Escherichia coli A PARTIR DE PIOMETRA CANINA
}

\section{PROFILE OF RESISTANCE OF EScherichia coli ISOLATED FROM CANINE PYOMETRA}

\author{
Fernanda Santana Oliveira ${ }^{1}$ \\ Lucas Nogueira Paz ${ }^{1}$ \\ Tais Menezes Mota ${ }^{1}$ \\ Arianne Pontes Oriá ${ }^{1}$ \\ Maurício Costa Alves Da Silva ${ }^{1}$ \\ Melissa Hanzen Pinna ${ }^{1 *}$ \\ ${ }^{1}$ Universidade Federal da Bahia, Salvador, BA, Brasil. \\ *Autora para correspondência - melissahp@ufba.br
}

\begin{abstract}
Resumo
A piometra é uma enfermidade endotelial que acomete com mais frequência as fêmeas adultas e ativas reprodutivamente. Caracteriza-se por inflamação e acúmulo de exsudato na cavidade uterina que geralmente está associada a infecções bacterianas. O presente estudo objetivou avaliar o perfil de resistência de isolados de Escherichia coli a partir do conteúdo uterino de 42 fêmeas caninas, atendidas no Setor de Cirurgia de Pequenos Animais do Hospital de Medicina Veterinária da Universidade Federal da Bahia, com diagnóstico de piometra. Para a realização da análise bacteriológica, uma amostra do conteúdo uterino foi obtida imediatamente após o ato cirúrgico de ovariosalpingohisterectomia terapêutica $(\mathrm{OSH})$ e encaminhada para o laboratório. Após análise microbiológica observou-se uma predominância da bactéria Escherichia coli em 40,5\% (15/37). As cepas de Escherichia coli isoladas apresentaram os maiores índices de resistência aos antimicrobianos eritromicina $(93,3 \%)$, azitromicina $(80 \%)$, ampicilina, amoxacilina e cefalotina ( $40 \%$ cada). Tal estudo reforça a necessidade da realização do exame microbiológico com finalidade epidemiológica e correta aplicação terapêutica, evitando, com isso, a utilização indiscriminada de antimicrobianos e potencial surgimento de estirpes multirresistentes.
\end{abstract}

Palavras-chave: bactéria; multirresistência; útero.

\begin{abstract}
The endothelial pyometra is a disease that affects more frequently reproductively active adult females. Characterized by inflammation and accumulation of exudate in the uterine cavity, generally associated with bacterial infections. The present study aimed to evaluate the resistance profile of Escherichia coli isolates from 42 female dogs diagnosed with pyometra, seen at the Department of Small Animal Surgery, Hospital of Veterinary Medicine, Federal University of Bahia. To perform the bacteriological analysis, a sample of the contents of the uterus was obtained immediately after surgery of ovariosalpingohisterectomy therapy $(\mathrm{OSH})$ and sent to the laboratory. Microbiological analysis showed a predominance of the bacterium Escherichia coli in 40.5\% (15/37). Strains of Escherichia coli isolates showed higher rates of resistance to antimicrobial erythromycin (93.3\%), azithromycin (80\%), ampicillin, amoxicillin, and cephalothin (40\% each). This study reinforces
\end{abstract}


the need to perform the microbiological examination for epidemiological purposes and the correct therapeutic application, thereby avoiding the indiscriminate use of antimicrobials and the potential emergence of multidrug-resistant strains.

Keywords: bacteria; multiresistant; uterus.

Enviado em: 01 dezembro de 2015

Aceito em: 05 agosto de 2016

\section{Introdução}

O complexo hiperplasia endometrial cística-piometra é uma enfermidade endometrial que acomete com mais frequência fêmeas caninas adultas ativas reprodutivamente, comumente diagnosticada em cadelas entre sete e dez anos, sobretudo em países onde a castração não é uma prática rotineira ${ }^{(1-3)}$. Caracteriza-se por inflamação e acúmulo de exsudato na cavidade uterina que geralmente está associada a infecções bacterianas ${ }^{(4,5)}$, sendo resultante de complexos fatores etiológicos, como raça, influência hormonal no ambiente uterino, influência genética, virulência da bactéria infectante, gestações prévias e capacidade imune do hospedeiro. ${ }^{(2,6,7)}$

O crescimento e a atividade secretora das glândulas endometriais (proliferação endometrial) são estimulados pela progesterona que também reduz a atividade miometrial, levando a um acúmulo de líquido nas glândulas endometriais na luz uterina. A ruptura dos cistos endométricos e o acúmulo de material mucóide na luz uterina favorecem a invasão bacteriana secundária ascendente a partir da vagina. Essa condição possibilita a infecção bacteriana do corpo uterino e posteriormente uma piometra $^{(8)}$.

Estudos recentes sugerem uma similaridade entre os agentes bacterianos responsáveis pela piometra em cadelas e os que habitam normalmente a vagina, o trato urinário, o trato intestinal e a bursa ovariana $^{(9-11)}$. Dentre esses agentes, destaca-se Escherichia coli como a bactéria mais comumente responsável por quadros de piometra ${ }^{(4,11-14)}$; entretanto, outros microrganismos também já foram implicados na etiologia da doença como Pseudomonas spp., Staphylococcus sp., Streptococcus spp., Proteus sp., Klebsiella spp., Enterobacter cloacae, Corynebacterium spp., Hafnia alvei e Pasteurella $\operatorname{spp}^{(4,11,13,14)}$.

A piometra pode ocorrer de forma aberta ou fechada, de acordo com a presença ou ausência de secreção no canal vaginal ${ }^{(15)}$. O quadro de piometra de cérvix aberta pode cursar com hiperemia de vulva, além de secreção vaginal sanguinolenta e/ou purulenta ${ }^{(16)}$, enquanto em casos com cérvix fechada os sinais clínicos geralmente são mais graves, sobretudo porque há dificuldade na drenagem do conteúdo uterino ocasionando a ruptura do útero, contribuindo então para o agravamento do quadro de septicemia e endotoxemia, principalmente causados pela Escherichia coli ${ }^{(3,14,17)}$. Em ambos os casos, o tratamento cirúrgico é o mais indicado já que a retirada do útero elimina o foco infeccioso ${ }^{(3)}$.

De acordo com Smith ${ }^{(18)}$, a terapêutica deve ser instituída antes da cirurgia com o uso de fluidoterapia intravenosa para estabilização do paciente além de antimicrobianos de largo espectro. Sendo assim, o exame microbiológico é imprescindível para nortear a conduta terapêutica, uma vez que propiciará a identificação do agente etiológico, fornecerá dados prévios sobre a ocorrência bacteriana no ambiente hospitalar e propiciará o conhecimento do perfil de sensibilidade aos antimicrobianos.

Diante do exposto, o presente trabalho objetivou avaliar o conteúdo intrauterino de cadelas com diagnóstico de piometra atendidas no Setor de Cirurgia de Pequenos Animais do Hospital de Medicina Veterinária, da Universidade Federal da Bahia e testar os isolados bacterianos frente aos antimicrobianos mais utilizados na terapêutica veterinária. 


\section{Material e Métodos}

O presente estudo foi aprovado pela Comissão de Ética no Uso de Animais da Escola de Medicina Veterinária e Zootecnia da Universidade Federal da Bahia sob o número 06/2014. Utilizaram-se 42 fêmeas da espécie canina (Canis familiares), com idade variando de um a 16 anos, atendidas no Setor de Cirurgia de Pequenos Animais do Hospital de Medicina Veterinária da Universidade Federal da Bahia com diagnóstico de piometra. O diagnóstico da enfermidade foi realizado a partir do histórico, dos exames laboratoriais e ultrassonográfico, além dos sinais clínicos identificados no exame físico. Sendo a confirmação realizada durante a intervenção cirúrgica pela detecção de distensão da parede uterina em variados graus e pelo conteúdo do órgão.

Para a realização da análise bacteriológica, uma amostra do conteúdo intrauterino foi obtida imediatamente após o ato cirúrgico de ovariosalpingohisterectomia terapêutica $(\mathrm{OSH})$, por meio de punção uterina asséptica com auxílio de seringa de cinco mililitros e agulha descartável de $25 \times 7 \mathrm{~mm}$.

As amostras foram encaminhadas ao laboratório onde foram processadas em até meia hora, utilizandose a técnica de esgotamento por estrias em Agar Sangue de Carneiro a 6\%, Agar Eosina Azul de Metileno (EMB) e Caldo Triptose, sendo posteriormente incubadas a $37{ }^{\circ} \mathrm{C}$, por $24-48$ horas, em estufa de aerobiose. Em seguida, o crescimento bacteriano observado foi submetido à análise das características morfotintoriais e bioquímicas de acordo com as técnicas rotineiras do laboratório. Para as bactérias Gram-positivas, realizaram-se os testes de catalase, base para oxidação e fermentação (OF), fermentação de manitol e coagulase. Para as bactérias Gram-negativas a identificação foi feita por meio do Triplice Sugar and Iron (TSI), oxidase, indol, vermelho de metila, teste de motilidade, citrato de Simmons, uréia, malonato e fermentação dos carboidratos (adonitol, arabinose, dulcitol, glicose, lactose, manitol e sacarose).

Todas as cepas de Escherichia coli isoladas e identificadas foram submetidas ao teste de sensibilidade a antimicrobianos, por meio do método de difusão com discos, em ágar de Mueller \& Hinton ${ }^{(19)}$ utilizando-se os seguintes antimicrobianos, de acordo com a terapêutica adotada na rotina clínica: amicacina $(30 \mu \mathrm{g})$, amoxacilina $(10 \mu \mathrm{g})$, ampicilina $(10 \mu \mathrm{g})$, azitromicina $(15 \mu \mathrm{g})$, cefalexina $(30 \mu \mathrm{g})$, cefalotina $(30 \mu \mathrm{g})$, ciprofloxacina $(05 \mu \mathrm{g})$, cloranfenicol $(30 \mu \mathrm{g})$, eritromicina $(15 \mu \mathrm{g})$, gentamicina $(10$ $\mu \mathrm{g})$, neomicina $(30 \mu \mathrm{g})$, norfloxacina $(10 \mu \mathrm{g})$, polimixina B $(300 \mu \mathrm{g})$, sulfazotrim $(25 \mu \mathrm{g})$, tetraciclina $(30 \mu \mathrm{g})$, tobramicina $(10 \mu \mathrm{g})$. As leituras foram realizadas após 24 horas de incubação a $37^{\circ} \mathrm{C}$ e a interpretação realizada pela medida do diâmetro do halo de inibição do crescimento microbiano, classificando como sensível, intermediário, ou resistente. As concentrações bem como o critério de interpretação foram os recomendados pela "National Committee for Clinical Laboratory Standards NCCLS" em 2011.

\section{Resultados e Discussão}

Ao se analisar a distribuição dos casos de piometra em relação à idade observou-se que $73,8 \%$ das fêmeas apresentavam idade igual ou superior a seis anos. Dados similares foram obtidos por outros autores ao avaliarem cadelas com piometra na mesma faixa etária ${ }^{(1,2)}$. Esse resultado pode relacionarse com as longas e contínuas estimulações da progesterona na fase luteal, permitindo modificações no endométrio e consequentemente favorecendo a invasão bacteriana ${ }^{(15)}$.

Identificou-se crescimento bacteriano em 88,1\% (37/42) das amostras analisadas, com isolamento de 48 cepas, sendo 64,6\% (31/48) dos isolados Gram-negativos e 35,4\% (17/48) Gram-positivos. O percentual de isolamento bacteriano obtido no presente estudo corrobora os dados da literatura ${ }^{(4,12,20)}$. A ausência de crescimento bacteriano em algumas amostras de piometra pode ser atribuída à utilização 
prévia de antimicrobianos ou devido à hiperplasia endometrial cística (HEC), já que essa pode resultar em piometra, hematometra ou hidrometra. É sabidamente conhecida a dificuldade na diferenciação destas enfermidades reprodutivas; logo, algumas amostras podem não ter sido necessariamente advindas de piometra ${ }^{(21)}$.

A partir das amostras com crescimento bacteriano, observou-se que 73,0\% (27/37) representavam infecções simples, em que apenas uma cepa foi isolada, enquanto nas demais $27,0 \%$ (10/37) foi possível identificar duas ou mais espécies bacterianas na mesma amostra.

Em relação às infecções simples, observou-se uma predominância da bactéria Escherichia coli em 40,5\% (15/37) dos isolados, seguidas de Enterobacter spp. em 10,8\% (4/37), Staphylococcus spp. em 8,1\% (3/37), Klebsiella spp. em 5,4\% (2/37), Pseudomonas aeruginosa em 5,4\% (2/37) e Streptococcus spp. em 2,7\% (1/37), conforme apresentados na Tabela 1.

Tabela 1. Distribuição dos isolados microbianos, em infecções simples (27/37 - 73\%), provenientes de piometra canina do Hospital de Medicina Veterinária da Universidade Federal da Bahia

\begin{tabular}{lc}
\hline \multicolumn{1}{c}{ Microrganismo isolado } & Distribuição \\
\hline Escherichia coli & $15 / 37(40,5 \%)$ \\
Enterobacter spp & $4 / 37(10,8 \%)$ \\
Staphylococcus spp. & $3 / 37(8,1 \%)$ \\
Klebsiella spp. & $2 / 37(5,4 \%)$ \\
Pseudomonas aeruginosa & $2 / 37(5,4 \%)$ \\
Streptococcus spp. & $1 / 37(2,7 \%)$ \\
\hline Total & $\mathbf{7 3} \%$
\end{tabular}

A predominância de isolados de Escherichia coli a partir de amostras de casos de piometra canina, já foi documentada na literatura por outros autores ${ }^{(11,14,20,22)}$. De acordo com Sancka e Dhaliwal ${ }^{(23)}$, cepas de Escherichia coli associadas a casos de piometra canina são provenientes da microbiota intestinal, que ascendem e colonizam o trato urinário e o útero de cadelas, com posterior ocorrência de processo patológico. Outros autores ainda reforçam a ideia de migração fecal uterina, ao demonstrar características bioquímicas semelhantes de bactérias isoladas de amostras a partir de fezes e conteúdo intrauterino de cadelas com piometra. $\mathrm{O}$ trato urinário pode servir como um reservatório de cepas bacterianas que ascendem para o útero quando ocorre abertura da cérvix no período de proestro e estro $^{(9,10,24)}$.

As cepas de Escherichia coli isoladas apresentaram os maiores índices de resistência aos antimicrobianos eritromicina (93,3\%), azitromicina (80\%), ampicilina, amoxacilina e cefalotina com $40 \%$ cada. Papini et al. ${ }^{(25)}$, ao estudarem infecção do trato urinário em cães, identificaram $100 \%$ de resistência das cepas de Escherichia coli à eritromicina. Cruz, Paes e Siqueira ${ }^{(13)}$, ao avaliarem a susceptibilidade antimicrobiana de cepas isoladas em cães, também verificaram resistência de Escherichia coli à ampicilina $(62,96 \%)$ e azitromicina $(81,48 \%)$. De acordo com esses autores, a resistência aos antimicrobianos eritromicina e ampicilina vem aumentando nos últimos anos em decorrência da sua ampla utilização na rotina da clínica veterinária.

Considerando-se a resistência a três ou mais antimicrobianos testados, observou-se que 73,3\% das cepas de E.coli foram caracterizadas como multirresistentes. Tal constatação contribui para o sucesso na terapêutica instituída uma vez que se baseia no isolamento e identificação do agente e posterior detecção de sensibilidade não presumível, através da realização de antibiograma.

Em um estudo similar realizado por Lara et al. ${ }^{(26)}$ no Rio Grande do Sul, ao testarem 15 linhagens de $E$. coli isoladas de cadelas com piometra, os autores relataram multirresistência para ampicilina, 
amoxacilina, cefalotina, ciprofloxacina, enrofloxacina, gentaminica e norfloxacina. Em outro estudo semelhante utilizando 27 isolados, observou-se que dez cepas apresentaram resistência a pelo menos um antimicrobiano, enquanto as demais apresentaram multirresistência principalmente a sulfadiazina, tetraciclina, estreptomicina, ampicilina e amoxacilina com ácido clavulânico ${ }^{(27)}$. É citado também resistência a outras drogas, azitromicina, doxiciclina, ceftiofur, florfenicol, cefalexina, oxitetraciclina, clorafenicol. Esses resultados deixam claro que o tratamento sem o respaldo de testes de sensibilidade microbiana, utilização de drogas na experiência de terapias anteriores ou no apelo comercial dos produtos tende com o tempo a contribuir para o surgimento de estirpes multirresistentes ${ }^{(26,27)}$. Além disso, já foi evidenciada resistência bacteriana a antibióticos de uso restrito em humanos em cepas isoladas de infecções variadas provenientes de cães, o que sugere que houve transmissão de genes de resistência, possivelmente pela proximidade entre humanos e esses animais, destacando assim a resistência microbiana como um problema de saúde pública ${ }^{(13)}$.

Em relação à sensibilidade dos isolados de Escherichia coli, verificou-se que a tobramicina foi a droga mais eficaz no controle do crescimento microbiano seguida por sulfazotrim e norfloxacina. Siqueira et al. ${ }^{(28)}$, ao investigarem a susceptibilidade de cepas de Escherichia coli oriundas de piometra canina, encontraram maior sensibilidade para norfloxacina, dados esses que corroboram com o presente estudo. Contudo, alguns pesquisadores vêm demonstrando a presença de diferentes perfis de sensibilidade, sendo considerados os antimicrobianos de maior sensibilidade a cefalexina, enrofloxacina, gentamicina, ciprofloxacina, amoxacilina, amoxacilina com ácido clavulânico e ampicilina em cães diagnosticados com piometra ${ }^{(13,11,27)}$.

Sendo assim, a obtenção de isolados locais a partir de casos clínicos é de fundamental importância para nortear a terapêutica a ser instituída de acordo com a sensibilidade antimicrobiana, além de contribuir significativamente para o monitoramento microbiológico dos ambientes hospitalares.

\section{Conclusão}

A avaliação do conteúdo intrauterino de cadelas com diagnóstico de piometra atendidas no Setor de Cirurgia de Pequenos Animais do Hospital de Medicina Veterinária, da Universidade Federal da Bahia evidenciou a predominância de isolados de Escherichia coli, com elevado percentual de multirresistência frente aos antimicrobianos mais utilizados na terapêutica veterinária.

\section{Referências}

1. Gibson A, Dean R, Yates D, Stavisky J. A retrospective study of pyometra at five RSPCA hospitals in the UK: 1728 cases from 2006 to 2011. Vet Rec [Internet]. 2013;173(16):396. Disponivel em: http://www. pubmedcentral.nih.gov/articlerender.fcgi? artid $=3812855 \&$ tool=pmcentrez $\&$ rendertype $=$ abstract

2. Hagman R, Lagerstedt AS, Hedhammar Å, Egenvall A. A breed-matched case-control study of potential risk-factors for canine pyometra. Theriogenology. 2011;75(7):1251-7.

3. Jitpean S, Ström-Holst B, Emanuelson U, Höglund OV, Pettersson A, Alneryd-Bull C, et al. Outcome of pyometra in female dogs and predictors of peritonitis and prolonged postoperative hospitalization in surgically treated cases. BMC Vet Res [Internet]. 2014;10(1):6. Disponivel em: http://www.biomedcentral.com/1746$\underline{6148 / 10 / 6}$

4. Adamovich-Rippe KN, Mayhew PD, Runge JJ, Culp WTN, Steffey MA, Mayhew KN, et al. Evaluation of laparoscopic-assisted ovariohysterectomy for treatment of canine pyometra. Vet Surg. 2013;42(5):572-8. 
5. Mir F, Fontaine E, Albaric O, Greer M, Vannier F, Schlafer DH, et al. Findings in uterine biopsies obtained by laparotomy from bitches with unexplained infertility or pregnancy loss: An observational study. Theriogenology. 2013;79(2):312-22.

6. Hagman R, Kindahl H, Fransson BA, Bergström A, Holst BS, Lagerstedt AS. Differentiation between pyometra and cystic endometrial hyperplasia/mucometra in bitches by prostaglandin F2 $\alpha$ metabolite analysis. Theriogenology. 2006;66(2):198-206.

7. Jitpean S, Hagman R, Ström-Holst B, Höglund OV, Pettersson A, Egenvall A. Breed Variations in the Incidence of Pyometra and Mammary Tumours in Swedish Dogs. Reprod Domest Anim. 2012;47(SUPPL. 6):347-50.

8. Trindade AB, Brun MV, Basso PC, Oliveira NF, Bertoletti B, Bortolini CE, et al. Ovário-histerectomia videoassistida em uma cadela com hematometra- Relato de caso. Ciênc. anim. bras. 2010;11(1):226-33.

9. Chen YMM, Wright PJ, Lee CS, Browning GF. Uropathogenic virulence factors in isolates of Escherichia coli from clinical cases of canine pyometra and feces of healthy bitches. Vet Microbiol. 2003;94(1):57-69.

10. Mateus L, Henriques S, Merino C, Pomba C, Lopes da Costa L, Silva E. Virulence genotypes of Escherichia coli canine isolates from pyometra, cystitis and fecal origin. Vet Microbiol. 2013;166(3-4):590-4.

11. Rubio A, Boyen F, Tas O, Kitshoff A, Polis I, Van Goethem B, et al. Bacterial colonization of the ovarian bursa in dogs with clinically suspected pyometra and in controls. Theriogenology [Internet]. 2014;82(7):96671. Disponivel em: http://linkinghub.elsevier.com/retrieve/pii/S0093691X14003574

12. Agostinho JMA, De Souza A, Schocken-Iturrino RP, Beraldo LG, Borges CA, Ávila FA, et al. Escherichia coli strains isolated from the uteri horn, mouth, and rectum of bitches suffering from pyometra: Virulence factors, antimicrobial susceptibilities, and clonal relationships among strains. Int J Microbiol. 2014;2014.

13. Cruz AR, Paes AC, Siqueira AK. Perfil de sensibilidade de bactérias patogênicas isoladas de cães frente a antimicrobianos. Veterinária e Zootecnia. 2012;19(4):601-10.

14. Kalenski TDA, Reinoldes A, Kitsis M, Faustino M, Talib MSF, Cortopassi SRG. Identificação das bactérias envolvidas na sepse grave de fêmeas caninas com piometra submetidas a ovário-histerectomia terapêutica. Brazilian J Vet Res Anim Sci [Internet]. 2012;49(2):130. Disponivel em: http://www.revistas.usp.br/bjvras/ $\underline{\text { article/view/40269 }}$

15. Volpato R, Martin I, Ramos RS, Tsunemi MH, Laufer-Amorin R, Lopes MD. Imunoistoquímica de útero e cérvice de cadelas com diagnóstico de piometra. Arq Bras Med Vet e Zootec. 2012;64(5):1109-17.

16. Quessada AM, Lima WC, Lima DASD, Rodrigues NM, Rodrigues MC, Rufino PHQ, et al. Piometra iatrogênica em cadela: relato de caso Iatrogenic pyometra in a bitch: a case report. Rev Bras Reprod Anim [Internet]. 2014;38(3):182-5. Disponivel em: http://www.cbra.org.br/pages/publicacoes/rbra/v38n3/pag181184\%28RB517\%29.pdf

17. Kunkitti P, Srisuwatanasagul S, Chatdarong K. Distribution of estrogen receptor alpha and progesterone receptor, and leukocyte infiltration in the cervix of cyclic bitches and those with pyometra. Theriogenology [Internet]. Elsevier Inc.; 2011;75(6):979-87. Disponivel em: http://dx.doi.org/10.1016/j. theriogenology.2010.11.004

18. Smith FO. Canine pyometra. Theriogenology. 2006;66(3 SPEC. ISS.):610-2.

19. Bauer AW, Kirby MM, Sherris JC, Truck M. Antibiotic susceptibility testing by a standardized single disk method. Am J Clin Pathol 1966; 45: 493-6

20. Sanches FCS, Pereira GQ, Filho MDM, Silva LC, Okano W, Kemper DAG, et al. Avaliação bacteriológica 
uterina de cadelas com piometra. Rev Bras Hig e Sanidade Anim. 2015;9(1):111-21.

21. Pretzer SD. Clinical presentation of canine pyometra and mucometra: A review. Theriogenology. 2008;70(3):359-63

22. Krekeler N, Marenda MS, Browning GF, Holden KM, Charles JA, Wright PJ. The role of Type 1, P and S fimbriae in binding of Escherichia coli to the canine endometrium. Vet Microbiol. 2013;47(suppl. 6):331-334;

23. Sancak AA, Dhaliwal GK. DNA hybridization of Escherichia coli strains isolated from uteri and fecal samples of bitches with pyometra. Turkish J Vet Anim Sci. 2004;28(5):857-63.

24. Siqueira AK, Ribeiro MG, Leite DDS, Tiba MR, Moura C De, Lopes MD, et al. Virulence factors in Escherichia coli strains isolated from urinary tract infection and pyometra cases and from feces of healthy dogs. Res Vet Sci [Internet]. Elsevier Ltd; 2009;86(2):206-10. Disponivel em: http://dx.doi.org/10.1016/j. rvsc.2008.07.018

25. Papini R, Ebani VV, Cerri D, Guidi G. Survey on bacterial isolates from cats with urinary tract infections and their in vitro sensitivity in Italy. Rev Med Vet (Toulouse) [Internet]. 2003;154(1):27-32. Disponivel em: $\underline{\mathrm{http}} / / / \mathrm{www} . \mathrm{scopus} . \mathrm{com} / \mathrm{inward} / \mathrm{record}$.url?eid=2-s2.0-0037255279\&partnerID=40\&md5=c598a141ec4d0a02 $\underline{\text { fbaa9aa5e } 045 \mathrm{fda}}$

26. Lara VM, Donadeli MP, Cruz FSF, Carregaro AB. Multirresistência antimicrobiana em cepas de Escherichia coli isoladas de cadelas com piometra. Arq Bras Med Vet e Zootec. 2008;60(4):1032-4.

27. Ghanbarpour R, Akhtardanesh B. Genotype and antibiotic resistance profile of Escherichia coli strains involved in canine pyometra. Comp Clin Path. 2012;21(5):737-44.

28. Siqueira AK, Ribeiro MG, Salerno T, Takahira RK, Lopes MD, Prestes NC, et al. Perfil de sensibilidade e multirresistência em linhagens de Escherichia coli isoladas de infecção do trato urinário, de piometra e de fezes de cães. Arq Bras Med Vet e Zootec. 2008;60(5):1263-6. 